\title{
Pengaruh Physical Evidence terhadap Loyalitas Nasabah Bank Syariah: Peran Kepuasan sebagai Variabel Pemediasi
}

\author{
Muhammad Basyir \\ Fakultas Ekonomi dan Bisnis, Universitas Syiah Kuala, Banda Aceh, Indonesia.
}

\begin{abstract}
Abstrak. Penelitian ini menganalisis pengaruh physical evidence terbadap kepuasan dan loyalitas nasabah bank syariah di Banda Aceh. Bank syariah yang dimaksudkan tediri dari Bank. Aceh Syariah, BRI Syariah, BNI Syariah, Bank Mandiri Syariah, dan Bank Danamon Syariah. Pengumpulan data melalui penyebaran kuesioner kepada 250 orang nasabah yang ditentukan secara purposive sampling. Menggunakan statistik multivariat structural equation modeling (SEM) sebagai alat analisis data, penelitian menemukan bahwa physical evidence secara nyata berpengaruh positif terhadap kepuasan dan loyalitas nasabah. Keberadaan kepuasan nasabah memediasi pengarub physical evidence terhadap loyalitas nasabah.
\end{abstract}

Kata kunci: Physical evidence, kepuasan nasabah, loyalitas nasabab dan structural equation modeling.

Abstract. This study analyzes the effect of physical evidence on customer satisfaction and loyalty of sharia banks in Banda Aceh. The sharia banks comprise Bank. Aceh Syariah, BRI Syariah, BNI Syariah, Bank Mandiri Syariah, and Bank Danamon Syariah. Data gathering through distributing questionnaires to 250 customers who were determined by purposive sampling. Using multivariate statistical structural equation modeling (SEM) as a data analysis means, the study found that physical evidence has a positive effect on customer satisfaction and loyalty. The existence of customer satisfaction mediates the effect of physical evidence on customer loyalty.

Keywords: Physical evidence, customer's satisfaction, customer's loyalty and structural equation modeling. 


\section{Pendahuluan}

Bank syariah memiliki peran penting dalam mendorong perekonomian Indonesia. Kehadiran lembaga keuangan tersebut tidak hanya bermanfaat bagi masyarakat untuk memenuhi kebutuhan pembiayaan, tetapi juga menjadi salah satu alternatif terbaik ketika mereka ingin menyimpan dana dalam bentuk tabungan (Ikhsan et al., 2020). Kelangsungan usaha bank syariah tidak terlepas dari sejauhmana layanan yang diberikan mampu memenuhi kebutuhan masyarakat, terutama nasabah pembiayaan dan nasabah tabungan. Apalagi mereka memiliki preferensi tersendiri dalam memanfaatkan layanan lembaga keuangan bank (Amri et al., 2018). Ketika layanan yang mereka rasakan sesuai dengan harapan, maka kondisi tersebut dapat membentuk kepuasan yang pada gilirannya berdampak pada loyalitas mereka dalam menggunakan layanan. Sebaliknya, ketidakmampuan bank dalam memenuhi harapan nasabah mendorong mereka untuk beralih ke bank lain yang mereka anggap lebih baik (Sanjaya \& Pratiwi, 2018). Hal ini menjelaskan bahwa kepuasan dan loyalitas nasabah menjadi faktor kunci bagi keberlangsungan usaha lembaga keuangan bank termasuk bank syariah.

Pentingnya loyalitas nasabah bagi eksistensi bank syariah dalam menyelenggarakan layanan jasa keuangan telah menarik perhatian para peneliti keuangan syariah (Saeed et al., 2014; Yusof \& Arifin, 2016). Mereka berupaya mengungkapkan sejumlah faktor dalam menjelaskan perilaku nasabah dalam menggunakan bank tersebut. Loyalitas nasabah terhadap bank syariah dipengaruhi oleh kesadaran tentang pentingnya produk halal (Maulan, 2016), layanan karyawan (Sanjaya \& Pratiwi, 2018). Penelitian lainnya seperti yang dilakukan oleh Suhartanto et al. (2018) mengungkapkan bahwa loyalitas nasabah dipengaruhi oleh kepercayaan terhadap layanan yang diberikan. Kajian Widyarini (2018) membuktikan bahwa loyalitas nasabah secara nyata dipengaruhi oleh kepuasan dan kepercayaan mereka terhadap lembaga keuangan.

Dalam kontek Aceh, menjadi hal yang menarik untuk mengkaji kepuasan dan loyalitas nasabah bank syariah. Sebagai daerah penerapan syariat Islam, kehadiran bank syariah di Aceh mendapat tempat tersendiri di masyarakat. Namun tidak dapat dipungkiri bahwa lembaga keuangan bank yang sifatnya konvensional juga masih diminati oleh masyarakat. Indikasi tersebut secara nyata dapat dilihat dari munculnya pro dan kontra dalam merespon lahirnya Qanun 11/2018 tentang Lembaga Keuangan Syariah (LKS) yang mewajibkan seluruh lembaga keuangan di Aceh dijalankan berdasarkan prinsip syariah.

Terlepas dari adanya pro dan kontra tentang terkait dengan penerapan qanun tersebut, bank syariah di Aceh dan bank umum lainnya yang sedang berupaya mengalihkan prinsip kegiatan operasionalnya dari konvensional menjadi syariah berusaha meningkatkan pelayanannya. Upaya tersebut diantaranya dilakukan dengan memberikan perhatian terhadap bukti fisik (physical evidence) yang digunakan dalam menyelenggarakan layanan jasa perbankan. Physical evidence meliputi katagori fisik (tangible) atau semua produk fisik yang tersedia dalam mendukung kegiatan operasional penyedia layanan dan merupakan bagian tidak terpisahkan dari pelayanan itu sendiri (Mukhsina \& Brahmatih, 2014). Kendatipun upaya perbaikan bukti fisik terus dilakukan oleh bank syariah, namun hasil survei awal melalui wawancara dengan sejumlah nasabah lembaga keuangan bank di Banda Aceh mengindikasikan bahwa perilaku mereka dalam memanfaatkan layanan jasa keuangan dari bank tersebut relatif berbeda. Sebagian diantara mereka tidak begitu tertarik menggunakan layanan jasa bank syariah. Alasan yang mereka lakukan tidak hanya terkait dengan kemudahan dalam memanfaatkan layanan, tetapi juga berhubungan dengan fasilitas fisik (physical evidence) yang dimiliki oleh bank dalam melayani kebutuhan nasabahnya.

Kajian mengenai loyalitas dan kepuasan nasabah bank syariah dengan menempatkan physical evidence sebagai exogenous variable belum banyak diungkapkan oleh peneliti. Kalau pun ada, temuan yang mereka belum memberikan kesimpulan yang seragam. Tjan (2015) membuktikan bahwa physical evidence berpengaruh positif dan signifikan terhadap kepuasan dan loyalitas. Temuan yang sama juga diungkapkan oleh Ya-Ling Wu \& Eldon (2018) menyimpulkan 
bahwa kepuasan dan loyalitas nasabah terkait dengan penilaian mereka terhadap fasilitas fisik yang menyertai pelayanan. Berbeda dengan kedua peneliti tersebut, hasil kajian Chen \& Liu (2017) mengungkapkan bahwa kendatipun physical evidence berpengaruh positif terhadap kepuasan, namun pengaruh tersebut tidak signifikan. Kajian empiris yang dilakukan oleh Sanjaya \& Pratiwi (2018) dalam penelitian mereka juga mengungkapkan bahwa pyhsical evidence tidak berpengaruh terhadap loyalitas nasabah bank syariah.

Temuan sejumlah peneliti di atas mengindikasikan bahwa pengaruh physical evidence terhadap kepuasan dan loyalitas nasabah bank syariah masih menjadi pertanyaan terbuka. Artinya, belum ada satu kesimpulan yang akurat tentang signifikansi pengaruh variabel tersebut dalam menjelaskan kepuasan dan loyalitas nasabah. Ketika upaya perbaikan kualitas pelayanan bank syariah di Banda Aceh dilakukan melalui peningkatan physical evidence maka dipandang perlu untuk mengkaji sejauhmana kebijakan tersebut dapat berdampak terhadap peningkatan kepuasan dan loyalitas nasabah.

Secara sistematis, paper ini disusun dalam lima bagian. Bagian kedua mendeskripsikan landasan teori yang diperkuat dengan bukti empiris mengenai keterkaitan antar variabel, dan pengembangan hipotesis. Bagian ketiga menjelaskan metode penelitian mulai dari populasi dan penarikan sampel, skala pengukuran hingga model analisis data. Bagian keempat adalah hasil penelitian dan pembahasannya. Terakhir, bagian kelima mendeskripsikan kesimpulan penelitian dan rekomendasi bagi peneliti selanjutnya.

\section{Literature Review Pengembangan Hipotesis}

dan

\section{Pengaruh Physical Evidence terhadap Kepuasan Konsumen}

Physical evidence merupakan bagian tidak terpisahkan dari proses pelayanan, seperti halnya layanan jasa perbankan. Dimensi bauran pemasaran tersebut dapat diidentifikasi sebagai bukti fisik yakni fasilitas pelayanan dan peralatan yang melekat pada pelayanan itu sendiri. Bahkan tidak hanya terbatas pada peralatan yang digunakan dalam memberikan pelayanan, tetapi juga termasuk sirkulasi udara dan kebersihan ruang pelayanan (Lentell, 2000). Physical evidence meliputi katagori fisik (tangible) atau semua produk fisik yang disajikan kepada konsumen sebagai bagian dari pelayanan (Mukhsina \& Brahmatih, 2014). Dalam kontek perusahaan jasa keuangan bank, bukti fisik tersebut antara lain berkaitan dengan segala faktor yang berhubungan dengan bangunan, area parkir, peralatan pendukung layanan, ruang tunggu, dan kebersihan ruangan (Nashem et al., 2018). Chen \& Liu (2017) dalam kajian mereka menggunakan sejumlah indikator untuk mengukur physical evidence terdiri dari tampilan ruangan pelayanan, dekorasi ruangan yang menyenangkan, lingkungan atau peralatan yang mengurangi kejenuhan diruang pelayanan, dan lingkungan pelayanan secara umum.

Secara umum pengguna layanan memiliki kepentingan terhadap physical evidence sehubungan dengan pelayanan yang mereka terima. Phsyical evidence tidak hanya merupakan faktor penentu kelancaran pelayanan, tetapi juga dapat berdampak pada rasa nyaman dan kepuasan pengguna layanan. Adanya hubungan fungsional antara physical evidence dan loyalitas konsumen telah dibuktikan oleh sejumlah peneliti. Said et al. (2016) membuktikan bahwa physical evidence berdampak positif terhadap kepuasan konsumen. Sebelumnya, penelitian Wahid et al (2012) juga membuktikan bahwa kepuasan konsumen secara signifikan dipengaruhi oleh physical evidence. Berdasarkan uraian tersebut, hipotesis pertama penelitian ini adalah:

\section{$\mathrm{H}_{1}$ : Physical evidence berpengaruh terhadap kepuasan nasabah bank syariah}

\section{Pengaruh Physical Evidence terhadap Loyalitas Konsumen}

Bukti fisik sehubungan dengan penyampaian pelayanan dapat memberikan kesan tersendiri bagi pengguna layanan (Kushwaha et al., 2015). Karena itu, penyedia layanan harus berusaha agar bukti fisik yang merupakan bagian tidak terpisahkan dari pelayanan itu sendiri, dapat dipersepsikan baik oleh konsumennya. Sejumlah penelitian empiris membuktikan adanya hubungan searah antara penilaian pengguna jasa 
terhadap physical evidence dengan loyalitas mereka dalam menggunakan layanan. Seperti halnya penelitian Susanty \& Kenny (2015) menyimpulkan bahwa physical evidence berdampak signifikan terhadap peningkatan loyalitas konsumen. Penelitian Shen \& Bae (2018) juga memberikan kesimpulan yang sama bahwa loyalitas konsumen secara nyata dipengaruhi oleh penilaian mereka terhadap fasilitas fisik yang menyertai penyampaian layanan.

Loyalitas nasabah bank syariah tentunya juga dapat dikaitkan dengan physical evidence sebagai salah satu bauran pemasaran jasa keuangan. Apalagi physical evidence merupakan sumber daya utama setelah karyawan dalam mendukung kegiatan operasional bank tersebut. Karena itu, hipotesis kedua dinyatakan sebagai.

$\mathrm{H}_{2} \quad$ : Physical evidence berpengaruh terhadap loyalitas nasabah bank syariah.

\section{Pengaruh Kepuasan terhadap Loyalitas Konsumen}

Dalam perusahaan jasa, kepuasan konsumen merefleksikan perasaan mereka (puas tidak puas) yang mereka rasakan setelah menerima pelayanan (Farnita \& Amri, 2013). Dalam perusahaan jasa keuangan, kepuasan nasabah merupakan gambaran dari kemampuan perusahaan tersebut dalam memenuhi harapan nasabahnya (Saeed et al., 2014). Nasabah akan menemukan kepuasan ketika layanan yang mereka peroleh sesuai dengan harapan mereka (Oliver, 1997). Sebaliknya, ketidakpuasan akan muncul ketika layanan yang mereka rasakan lebih rendah dari yang mereka harapkan.

Adanya keterkaitan antara kepuasan dan loyalitas konsumen perusahaan jasa telah dibuktikan oleh sejumlah peneliti. Susanty \& Kenny (2005) dalam penelitian mereka mengungkapkan bahwa konsumen yang puas akan cenderung memanfaatkan layanan perusahaan secara berulang-ulang dan bahkan merekomendasikan perusahaan tersebut kepada orang lain. Perilaku pembelian ulang dan kemauan untuk merekomendasikan layanan ini merupakan indikator penting dalam pengukuran loyalitas. Temuan tersebut diperkuat oleh hasil penelitian Kusumawati et al (2017) dan Verma \& Singh (2017) yang juga membuktikan adanya pengaruh positif dan signifikan kepuasan terhadap loyalitas konsumen. Penelitian Loebis et al. (2018) juga mengungkapkan adanya pengaruh positif dan signifikan kepuasan terhadap loyalitas konsumen.

Didasarkan pada teori dan literatur empiris di atas, maka hipotesis ketiga dapat dinyatakan sebagai berikut.

$\mathrm{H}_{3}$ : Kepuasan berpengaruh terhadap loyalitas nasabah bank syariah.

\section{Metodologi Penelitian}

Penelitian dilakukan terhadap nasabah bank syariah di kota Banda Aceh. Bank syariah tersebut terdiri dari Bank Aceh Syariah, BRI Syariah, BNI Syariah, Bank Mandiri Syariah, dan Bank Danamon Syariah. Nasabah yang dipilih adalah nasabah tabungan yang diambil secara purposive sampling dengan ketentuan sudah menjadi nasabah lebih dari 1 tahun, dan selain menjadi nasabah bank syariah tertentu, nasabah juga sudah pernah menjadi nasabah bank konvensional. Kriteria ini penting agar mereka yang dijadikan sampel penelitian adalah nasabah yang telah memiliki pengalaman dengan layanan jasa perbankan. Jumlah sampel dibatasi hanya pada 250 orang nasabah yang memenuhi kriteria di atas.

Sebagaimana dijelaskan sebelumnya, penelitian ini mengoperasionalkan tiga variabel terdiri dari loyalitas nasabah, kepuasan nasabah dan physical evidence. Loyalitas nasabah merefleksikan kecenderungan nasabah secara sukarela dan terus menerus menjadi nasabah perusahaan jasa perbankan di masa yang akan datang (Lovelock \& Wright, 2012). Pengukuran variabel ini menggunakan sejumlah indikator terdiri dari komitmen untuk memanfaatkan layanan jasa bank, mau meningkatkan frekuensi memanfaatkan layanan, merekomendasikan bank kepada orang lain, memanfaatkan layanan tanpa pertimbangan, mengikuti informasi yang berkaitan dengan bank, keinginan untuk menjadi nasabah tetap, dan kemauan untuk mencerikan hal-hal positif (tentang bank) kepada orang lain (Giddens \& Hofmann, 2012). Selanjutnya kepuasan nasabah dilihat sebagai hasil evaluasi nasabah secara subjektif pelayanan bank yang 
mereka manfaatkan sesuai atau bahkan melebih harapan mereka. Pengukuran variabel ini mengadopsi Miles et al. (2012) yang kemudian disesuaikan dengan kepentingan penelitian, terdiri dari sejumlah indikator meliputi manfaat diterima sesuai dengan harapan, bank mampu memenuhi kebutuhan akan layanan jasa keuangan, perasaan bangga menjadi nasabah bank, perasaan senang memanfaatkan layanan bank, kesesuaian antara pengorban yang dikeluarkan dengan manfaat yang diterima, dan tidak pernah kecewa terhadap bank. Terakhir, physical evidence berkaitan dengan tampilan dan fasilitas fisik yang dimiliki bank dalam menyelenggarakan layanan jasa perbankan. Variabel ini diukur dengan sejumlah indikator yang dikembangkan dari Payne (2000) terdiri dari tampilan fisik (gedung), interior ruangan tunggu, kerapian ruang tunggu, dekorasi ruang pelayanan, ketersediaan tempat duduk, dan ketersediaan tempat parkir.

Pengumpulan data dilakukan melalui penyebaran kuesioner kepada nasabah. Kuesioner tersebut berisi pernyataan yang yang dikembangkan dari indikator pengukuran variabel seperti diuraikan di atas. Setiap pernyataan disediakan alternatif pilihan jawaban dalam bentuk tingkat kesetujuan yang akan dipilih oleh nasabah. Loyalitas dan kepuasan nasabah serta penilaian mereka terhadap physical evidence terkait dengan layanan jasa bank syariah dilihat dari tingkat kesetujuan yang mereka berikan pada masing-masing pernyataan.

Mengingat data yang dioperasionalkan merupakan data kualitatif, maka diperlukan adanya proses kuantifikasi data tersebut. Dalam hal ini diperlukan adanya skala pengukuran. Skala pengukuran data yang digunakan adalah skala Likert dengan bobot berkisar antara 1-5. Penggunaan skala likert untuk mengkuantatifkan data kualitatif telah dilakukan oleh sejumlah peneliti (Amri, 2012; Amri, 2013; Farnita \& Amri, 2013; Ratnawati \& Amri, 2013; Mora \& Basyir, 2018). Pemberian skala dilakukan terhadap masing-masing alternatif pilihan tingkat kesetujuan pada setiap item pernyataan kuesioner, dengan ketentuan tidak setuju $=1$, kurang setuju $=2$, ragu-ragu $=3$, setuju $=4$ dan sangat setuju $=5$.
Selanjutnya peralatan analisis data yang digunakan adalah structural equation modeling (SEM) yang dioperasionalkan dengan software AMOS 21. Penggunaan SEM sebagai alat analisis data melalui sejumlah tahapan, mulai dari confirmatory factor analysis (CFA), measurement model hingga menguji hubungan kausalitas antar variabel menggunakan full structural model. CFA digunakan untuk menguji validitas indikator dalam mengukur variabelnya dengan menjadikan nilai loading factor sebagai tolok ukurnya. Suatu indikator dinyatakan mampu merefleksikan variabel apabila memiliki nilai loading factor $>$ 0,70 (Ghozali, 2013). Sebaliknya indikator dinyatakan tidak valid jika hasil perhitungan statistik tidak memenuhi kriteria tersebut.

Selanjutnya measurement model mengacu pada sejumlah kriteria goodness of fit index terdiri dari perbandingan nilai $\mathrm{X}_{\text {hitung }}^{2}$ dan $\mathrm{X}_{\text {tabel, nilai }} \mathrm{p}$ value, GFI, AGFI, TLI, CFI, TLI dan RMSEA. Nilai $\mathrm{X}^{2}$ hitung diharapkan lebih kecil dari nilai $\mathrm{X}_{\text {tabel, }}^{2}$, nilai $\mathrm{p}$-value $>0,05$, nilai GFI dan AGFI $>0,90$, nilai TLI dan CFI $>0,95$ dan terakhir nilai RMSEA $<0,08$. Pemenuhan kriteria tersebut dapat memberikan kesimpulan bahwa model yang digunakan dalam menguji keterkaitan antar variabel dinyatakan good fit.

Terakhir, tahap full structural model dimaksudkan untuk melihat arah dan signifikansi hubungan fungsional antar variabel. Tolok ukur signifikansi pengaruh suatu variabel eksogen terhadap variabel endogennya didasarkan pada nilai $\mathrm{p}$-value dengan ketentuan p-value $<0,05$ mengindikasikan bahwa pada keyakinan 95\% variabel eksogen berpengaruh signifikan. Penerimaan atau penolakan hipotesis yang dinyatakan sebelumnya menggunakan krteria ini.

\section{Hasil dan Pembahasan}

\section{Hasil Confirmatory Factor Analysis dan Measurement Model}

Confirmatory factor analysis (CFA) mengestimasi faktor-faktor umum yang digunakan sebagai proxi dari variabel atau konstruk yang diukur. Analisis ini dapat menguji hipotesis tentang pengukuran dari perspektif teori (Xia \& Yang, 2018). CFA digunakan untuk menguji muatan faktor variabel yang diobservasi pada variabel laten. Tujuannya adalah menguji seberapa baik indikator yang digunakan dalam mengukur 
(suatu variabel) dapat merepresentasikan konsep teoritis (Hutchens, 2017).

Sebagaimana dijelaskan sebelumnya, variabel penelitian ini terdiri dari loyalitas nasabah, kepuasan nasabah dan physical evidence. Pengukuran masing-masing variabel tersebut menggunakan sejumlah indikator. Uji CFA dimaksudkan untuk mengetahui kemampuan suatu indikator dalam merefleksinya variabelnya. Indikasi tersebut didasarkan pada nilai loading factor yang dihasilkan melalui proses perhitungan statistik. Ghozali (2013) menyatakan, nilai loading factor yang dapat diterima di atas 0,70. Indikator dengan nilai loading factor $<0,70$ dinyatakan tidak valid sehingga harus direduksi dan model pengukuran.

Dalam kajian ini, uji Uji CFA dilakukan dua tahap. Hal ini disebabkan pada tahap pertama, terdapat satu indikator yang tidak memenuhi syarat, yakni indikator kedua yang berkaitan dengan loyalitas nasabah (LN2) dengan loading factor sebesar 0,473. Hal ini mengindikan bahwa indikator tersebut secara statistik dinyatakan tidak mampu merefleksikan loyalitas nasabah bank syariah. Setelah mereduksi LN2 sebagai observed variable bagi loyalitas nasabah, kemudian uji CFA dilanjutkan pada tahap kedua. Dalam tahap ini semua indikator telah memiliki nilai loading factor sesuai dengan yang dipersyaratkan. Untuk lebih jelasnya mengenai uji CFA tahap pertama dan kedua dapat dilihat Tabel 1.

Table 1. Hasil Confirmatory Factor Analysis

\begin{tabular}{|c|c|c|c|c|c|c|c|c|}
\hline & \multicolumn{3}{|c|}{ Uji CF A Tahap Pertama } & \multicolumn{3}{|c|}{ Uji CFA Tabap Kedua } \\
\hline & & & $\begin{array}{l}\text { Loading } \\
\text { Factor }\end{array}$ & $\begin{array}{l}\text { Critical } \\
\text { Ratio }\end{array}$ & p-value & $\begin{array}{l}\text { Loading } \\
\text { Factor }\end{array}$ & $\begin{array}{l}\text { Critical } \\
\text { Ratio }\end{array}$ & p-value \\
\hline LN1 & $<--$ & Loyalitas_Nasabah &, 762 & & &, 763 & & \\
\hline LN2 & $<--$ & Loyalitas_Nasabah & ,473 & 7,403 & & & & \\
\hline LN3 & $<--$ & Loyalitas_Nasabah &, 725 & 11,810 & **** & ,720 & 11,726 & **** \\
\hline LN4 & $<--$ & Loyalitas_Nasabah &, 778 & 12,811 & *** & .768 & 12,624 & *** \\
\hline LN5 & $<--$ & Loyalitas_Nasabah & ,866 & 14,534 & $* * *$ & ,870 & 14,620 & ***; \\
\hline LN6 & $<--$ & Loyalitas_Nasabah & ,834 & 13,910 & $* * *$ & 841 & 14,041 & $* * *$ \\
\hline LN7 & $<--$ & Loyalitas_Nasabah &, 724 & 11,787 & $* * *$ &, 722 & 11,757 & **** \\
\hline LN8 & $<--$ & Loyalitas_Nasabah &, 728 & 11,874 & $* * *$ &, 724 & 11,800 & **** \\
\hline $\mathrm{KN} 6$ & $<--$ & Kepuasan_Nasabah &, 756 & & &, 756 & & \\
\hline $\mathrm{KN} 5$ & $<--$ & Kepuasan_Nasabah &, 729 & 11,589 & $* * *$ &, 729 & 11,589 & **** \\
\hline $\mathrm{KN} 4$ & $<--$ & Kepuasan_Nasabah &, 731 & 11,628 & $* * *$ &, 732 & 11,629 & *** \\
\hline $\mathrm{KN} 3$ & $<--$ & Kepuasan_Nasabah &, 829 & 13,359 & $* * *$ & ,829 & 13,356 & *** \\
\hline $\mathrm{KN} 2$ & $<--$ & Kepuasan_Nasabah &, 770 & 12,311 & $* * *$ & ,770 & 12,308 & **** \\
\hline $\mathrm{KN} 1$ & $<--$ & Kepuasan_Nasabah &, 797 & 12,793 & *** &, 797 & 12,790 & **** \\
\hline PE6 & $<--$ & Physical_Evidence &, 761 & 12,329 & $* * *$ & ,761 & 12,331 & **** \\
\hline PE5 & $<--$ & Physical_Evidence &, 733 & 11,825 & $* * *$ &, 734 & 11,826 & **** \\
\hline PE4 & $<--$ & Physical_Evidence &, 856 & 14,090 & $* * *$ &, 856 & 14,089 & **** \\
\hline PE3 & $<--$ & Physical_Evidence & ,804 & 13,133 & $* * x$ & ,804 & 13,129 & **** \\
\hline PE2 & $<--$ & Physical_Evidence &, 775 & 12,593 & $* * *$ &, 775 & 12,590 & **** \\
\hline PE1 & $<--$ & Physical_Evidence &, 762 & & &, 762 & & \\
\hline
\end{tabular}

Sumber: Data Primer (Diolah), 2020.

Tabel 1 di atas memperlihatkan bahwa pada uji
FCA tahap kedua semua indikator sudah memiliki nilai loading factor $>0,70$. Hanya terdapat satu indikator yang direduksi atau dikeluarkan yakni indikator kedua pada variabel loyalitas nasabah. Sejalan dengan tahapan uji CFA, uji kelayakan model juga dilakukan dalam dua tahap. Hasil statistik measurement model seperti ditunjukkan dalam Tabel 2.

Tabel 2. Hasil Measurement Model

\begin{tabular}{|c|c|c|c|c|}
\hline $\begin{array}{c}\text { Tahapan } \\
\text { Pengujian }\end{array}$ & $\begin{array}{c}\text { Goodness-of-Fit } \\
\text { Index }\end{array}$ & Kriteria Nilai & Hasil & $\begin{array}{c}\text { Evaluasi } \\
\text { Model }\end{array}$ \\
\hline & $\chi^{2}-$ Chi-square & $\mathrm{X}^{2}{ }_{\text {hit }}<\mathrm{X}^{2}$ tab & $386,746>308,255$ & poor fit \\
& Probability & $\geq 0,05$ & 0,000 & poor fit \\
Tahap & GFI & $\geq 0,90$ & 0,742 & poor fit \\
Pertama & AGFI & $\geq 0,90$ & 0,689 & poor fit \\
& TLI & $\geq 0,95$ & 0,812 & marginal fit \\
& CFI & $\geq 0,95$ & 0,790 & poor fit \\
& RMSEA & $\leq 0,08$ & 0,110 & poor fit \\
\hline \multirow{5}{*}{ Tahap } & $\chi^{2}$ Chi-square & $\mathrm{X}^{2}{ }_{\text {hit }}<\mathrm{X}^{2}$ tab & $279,215<283,586$ & good fit \\
& Probability & $\geq 0,05$ & 0,061 & good fit \\
Kedua & GFI & $\geq 0,90$ & 0,921 & good fit \\
& AGFI & $\geq 0,90$ & 0,917 & good fit \\
& CFI & $\geq 0,95$ & 0,957 & good fit \\
& TLI & $\geq 0,95$ & 0,963 & good fit \\
& RMSEA & $\leq 0,08$ & 0,076 & good fit \\
\hline
\end{tabular}

Sumber: Data Primer (Diolah), 2020

Tabel 2 di atas memperlihatkan sejumlah kriteria yang berkaitan dengan goodness of fit index. Dalam pengujian tahap pertama, tidak satu pun kriteria terpenuhi dengan baik. Nilai $\mathrm{X}^{2}$ hitung $>\mathrm{X}^{2}$ tabel, nilai prob $<0,05$, nilai GFI dan AGFI $<0,90$, nilai TLI dan CFI $<0,095$ dan terakhir nilai RMSEA $>0,08$. Sehingga tidak satu pun dari kriteria tersebut yang dinyatakan good fit. Hal ini konsisten dengan hasil CFA pada tahap tersebut yang masih menunjukkan adanya indikator variabel dengan nilai loading factor dibawah 0,070.

Selanjutnya pada uji tahap kedua, semua kriteria sudah terpenuhi dimana $\mathrm{X}_{\text {hitung }}^{2}<\mathrm{X}^{2}$ tabel, nilai prob $>0,05$, nilai GFI dan AGFI $>0,90$, nilai TLI dan CFI $>0,95$ dan terakhir nilai RMSEA $<0,08$. Sehingga hasil evaluasi model pada tahap ini dinyatakan good fit untuk seluruh kriteria measurement model. Artinya, model pengukuran yang digunakan untuk menganalisis keterkaitan antar variabel dalam penelitian ini yakni loyalitas dan kepuasan nasabah bank syariah menggunakan physical evidence sebagai exogenous variable telah dinyatakan layak, sehingga dapat dilanjutkan pada tahap full structural model.

\section{Hasil Full Structural Model}

Sebagaimana dijelaskan dalam tahapan sebelumnya, hasil uji CFA dan measurement model dilakukan melalui dua tahapan. Pada tahap pertama, satu indikator yakni LN2 
tereduksi dari model karena memiliki nilai loading factor dibawah 0,70 . Pada tahap ini, uji measurement model juga belum menghasilkan kesimpulan yang good fit untuk seluruh kriteria yang digunakan. Selanjutnya pada tahap kedua semua indikator dinyatakan memenuhi syarat, dan semua kriteria goodness of fit index sudah terpenuhi secara baik. Langkah selanjutnya adalah melakukan uji full structural model SEM guna menentukan arah dan signifikansi pengaruh antar variabel. Hasilnya seperti ditunjukkan dalam Gambar 1.
Physical evidence berpengaruh positif dan signifikan terhadap kepuasan nasabah bank syariah, dengan koefisien estimasi sebesar 0,451 ( $\mathrm{p}$-value $<0,05$ ). Hal ini mengindikasikan bahwa semakin baik bukti fisik yang digunakan bank dalam menyelenggarakan layanan jasa perbankan semakin tinggi kepuasan nasabah. Dengan kata lain, peningkatan physical evidence secara nyata berdampak pada peningkatan kepuasan nasabah terhadap layanan yang mereka terima. Dengan demikian hipotesis $\left(\mathrm{H}_{1}\right)$ yang menyatakan physical evidence berpengaruh terhadap kepuasan nasabah

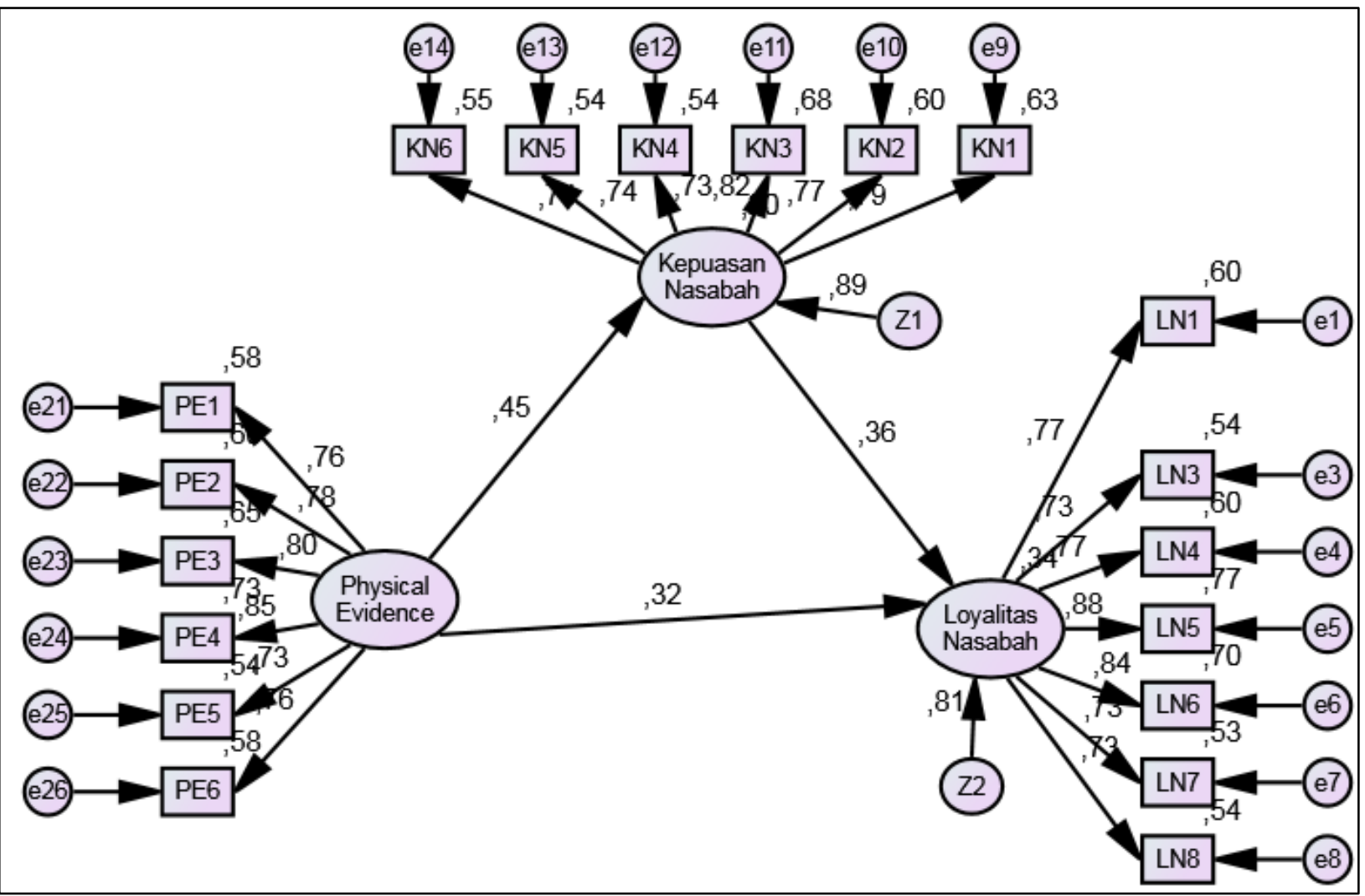

Gambar 1. Hasil Full Structural Model

Gambar 1 di atas tidak hanya memperlihatkan nilai koefisien estimasi masing-masing variabel eksogen terhadap variabel endogen, tetapi juga memperlihatkan nilai loading factor masingmasing indikator (manifest variable) terhadap variabel tersebut Nilai koefisien estimasi physical evidence terhadap kepuasan dan loyalitas nasabah bank syariah seperti dalam Tabel 3.

Tabel 3. Koefisien Estimasi Masing-masing Variabel

\begin{tabular}{|c|c|c|c|c|c|}
\hline Kepuasan_Nasabah & $<---$ & Physical_Evidence & $\begin{array}{c}\text { Estimate } \\
0,451\end{array}$ & $\begin{array}{l}\text { C.R.R } \\
6,290\end{array}$ & $\begin{array}{c}\mathrm{P} \text {-value } \\
* * *\end{array}$ \\
\hline Loyalitas_Nasabah & $<---$ & Kepuasan_Nasabah & 0,359 & 3,245 & $* * *$ \\
\hline Loyalitas_Nasabah & $<--$ & Physical_Evidence & 0,322 & 4,823 & *** \\
\hline
\end{tabular}

bank syariah dapat diterima. Temuan ini sesuai dengan pendapat Chopra (2014) yang menyatakan bahwa physical evidence merupakan aspek penting dalam penyampaian layanan kepada nasabah, dan secara nyata berdampak pada kualitas pelayanan. Selanjutnya pelayanan yang baik mendorong munculnya kepuasan pengguna layanan.

Adanya pengaruh physical evidence terhadap peningkatan kepuasan nasabah mengkonfirmasi temuan penelitian Lin \& Mattila (2010) dan Chen \& Liu (2017) yang secara empiris juga membuktikan bahwa kepuasan konsumen terhadap pelayanan yang mereka terima secara nyata dipengaruhi oleh penilaian mereka 
terhadap fasilitas fisik yang mendukung proses pelayanan tersebut. Semakin baik penilaian terhadap fasilitas fisik semakin tinggi kepuasan konsumen.

Selanjutnya physical evidence juga berpengaruh positif dan signifikan terhadap loyalitas nasabah bank syariah. Hal ini secara statistik ditunjukkan oleh koefisien estimai sebesar 0,322 (p-value < $0,05)$. Penilaian nasabah terhadap fasilitas fisik yang digunakan bank dalam memberikan layanan jasa perbankan, secara nyata dapat meningkatkan loyalitas nasabah. Dengan demikian hipotesis $\left(\mathrm{H}_{2}\right)$ yang menyatakan physical evidence berpengaruh terhadap loyalitas nasabah bank syariah dapat terima. Semakin baik persepsi nasabah terhadap physical evidence semakin tinggi loyalitas mereka menggunakan layanan bank syariah, sehingga terdapat hubungan searah dan signifikan antara loyalitas dan physical evidence. Temuan ini mengkonfirmasi temuan penelitian Bae et al. (2018) yang juga menyimpulkan bahwa peningkatan loyalitas konsumen secara nyata berhubungan searah dengan kelengkapan fasilitas fisik yang menyertai pelayanan itu sendiri. Temuan ini mendukung hasil penelitian Fida et al. (2020) yang juga membuktikan bahwa fasilitas fisik yang digunakan untuk menyelenggarakan layanan perbankan berdampak signifikan terhadap peningkatan loyalitas nasabah.

Kepuasan nasabah juga berpengaruh positif dan signifikan terhadap loyalitas nasabah bank syariah, dengan nilai koefisien estimasi sebesar $0,359$ ( $p$-value $<0,05)$. Peningkatan kepuasan nasabah secara nyata berdampak pada peningkatan loyalitas mereka dalam menggunakan layanan bank syariah. Dengan demikian hipotesis $\left(\mathrm{H}_{3}\right)$ yang menyatakan kepuasan berpengaruh terhadap loyalitas nasabah bank syariah dapat diterima. Nasabah yang puas akan cenderung memanfaatkan pelayanan secara berulang-ulang, menjadikan bank sebagai perioritas utama ketika ingin memanfaatkan layanan jasa keuangan dan bahkan merekomendasikan layanan jasa keuangan tersebut kepada orang lain. Hal inilah yang menyebabkan pengaruh positif kepuasan terhadap loyalitas nasabah. Temuan ini sejalan dengan hasil kajian Gong \& Yi (2018) yang juga membuktikan bahwa kepuasan dapat mendorong peningkatan loyalitas konsumen dalam memanfaatkan layanan jasa perusahaan. Temuan ini juga memperkuat temuan penelitian Slack \& Singh (2020) yang membuktikan bahwa

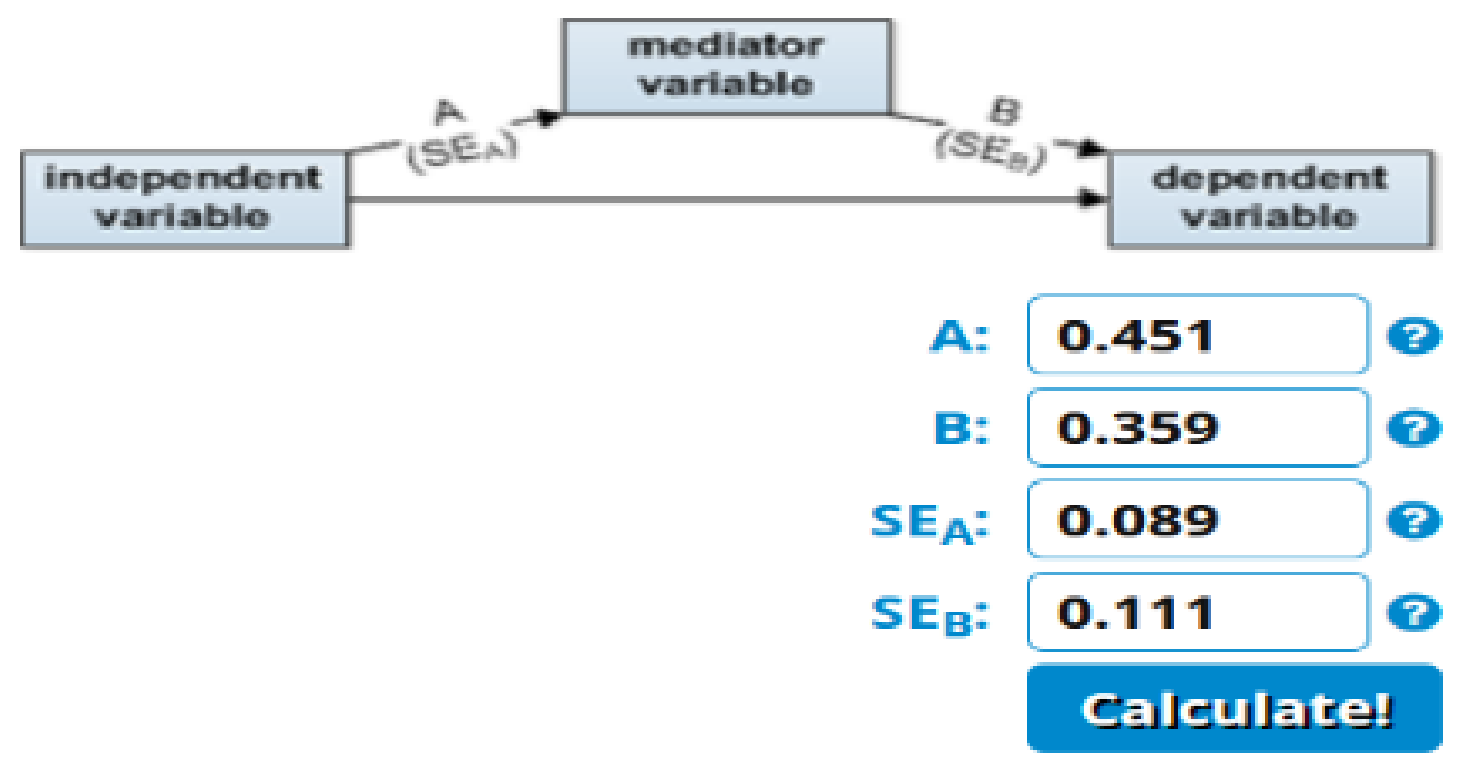

Sobel test statistic: $\mathbf{2 . 7 2 6 2 7 7 7 6}$ One-tailed probability: 0.00320265 Two-tailed probability: 0.00640531

Gambar 2. Hasil Sobel Test

133 | Jurnal Ekonomi dan Manajemen Teknologi Vol. 4 | No. 2 | 2020 
loyalitas konsumen secara nyata dipengaruhi oleh sejauhmana layanan yang diberikan mampu memenuhi kepuasan mereka. Ketika konsumen puas, maka kondisi tersebut secara nyata berdampak pada peningkatan loyalitas. Sebaliknya, kegagalan dalam memuaskan konsumen berdampak buruk terhadap loyalitas mereka.

Seperti ditunjukkan dalam Gambar 1 di atas, pengaruh physical evidence terhadap loyalitas nasabah bank Syariah selain terjadi secara langsung, juga dapat secara tidak langsung melalui kepuasan nasabah. Eksistensi kepuasan nasabah sebagai variabel pemediasi ditunjukkan oleh signifikansi pengaruh physical evidence terhadap kepuasan, dan pengaruh kepuasan terhadap loyalitas nasabah. Sebagaimana dijelaskan sebelumnya, pengaruh physical evidence terhadap kepuasan nasabah sangat signifikan, demikian juga halnya pengaruh kepuasan terhadap loyalitas nasabah. Hal ini secara statistik mengindikasikan bahwa kepuasan nasabah memainkan peran mediasi dalam hubungan sebab-akibat antara physical evidence dan loyalitas nasabah. Guna mempertajam analisis mengenai peran mediasi tersebut, pengujian efek mediasi kepuasan nasabah dalam hubungan fungsional antara loyalitas dan kepuasan nasabah menggunakan Sobel test. Sebagaimana hasil SEM dalam tabel 2 di atas, koefisien estimasi physical evidence terhadap kepuasan nasabah sebesar 0,451 dengan standar error sebesar 0,089. Selanjutnya koefisien estimasi kepuasan nasabah terhadap loyaitas nasabah sebesar 0,359 dengan standar error sebesar 0,111. Menggunakan Sobel test yang pengujiannya dilakukan secara online diperoleh nilai statistik seperti ditunjukkan dalam Gambar 2.

Berdasarkan perhitungan Sobel test diperoleh nilai statistik sebesar 2,726 dengan nilai p-value sebesar 0,006 $(<0,05)$. Hal ini mengindikasikan bahwa kepuasan nasabah memediasi pengaruh physical evidence terhadap loyalitas nasabah bank syariah. Meningkatnya persepsi physical evidence yang menyertai layanan jasa perbankan secara nyata meningkatkan loyalitas nasabah melalui kepuasan yang mereka rasakan dalam manfaatkan layanan tersebut.

\section{Kesimpulan dan Saran}

Penelitian ini menganalisis pengaruh physical evidence terhadap kepuasan dan loyalitas nasabah serta menganalisis eksistensi kepuasan nasabah sebagai intervening variable antara loyalitas nasabah dan physical evidence. Sampel penelitian sebanyak 250 orang nasabah yang diambil dari lima bank syariah di Banda Aceh. Menggunakan SEM sebagai model analisis data, penelitian menyimpulkan bahwa penilaian nasabah terhadap fasilitas fisik yang digunakan untuk menyelenggarakan layanan jasa perbankan berpengaruh positif dan signifikan terhadap kepuasan dan loyalitas nasabah. Kepuasan nasabah juga secara nyata dapat meningkatkan loyalitas nasabah bank syariah. Selain itu, kepuasan nasabah memediasi pengaruh physical evidence terhadap loyalitas. Kendatipun efek mediasi yang ditimbulkan merupakan partial mediation, namun eksistensi kepuasan dalam memediasi pengaruh physical evidence terhadap loyalitas nasabah sangat signifikan.

Penelitian ini berimplikasi bahwa upaya peningkatan kepuasan dan loyalitas nabasah bank syariah di Banda Aceh dapat dilakukan melalui intervensi kebijakan yang berhubungan dengan perbaikan physical evidence atau fasilitas fisik yang digunakan dalam menyelenggarakan layanan jasa perbankan. Jajaran manajemen bank syariah perlu memberikan perhatian lebih besar terhadap dimensi service marketing mix tersebut agar tuntutan terhadap pentingnya fasilitas fisik dapat terpenuhi dengan baik. Bagi peneliti akan datang yang tertarik untuk meneliti perilaku nasabah bank Syariah perlu memasukkan variabel lainnya sebagai predictor variable bagi loyalitas nasabah. Sehingga dapat diketahui dengan detail faktor-faktor apa saja yang secara empiris dapat membentuk loyalitas nasabah.

\section{Daftar Pustaka}

Amri, K. (2012). Faktor-faktor yang mempengaruhi kepercayaan pengguna layanan perawatan kecantikan, Jurnal Manajemen dan Keuangan, 1(1), 10-21. 
Amri, K. (2013). Faktor-faktor yang mempengaruhi loyalitas konsumen surat kabar Harian Serambi Indonesia di kota Banda Aceh. Jurnal Ekonomi Manajemen dan Bisnis, 1 (1), 229-242.

Amri, K., Qurratul'aini, I., \& Julianty, J. (2018). Preferensi nasabah memilih produk pembiayaan bank aceh syariah di kota Banda Aceh, Jurnal Samudra Ekonomi dan Bisnis, 9(1), 31-41.

Bae, S., Slevitch, L., \& Tomas, S. (2018). The effects of restaurant attributes on satisfaction and return patronage intentions: Evidence from solo diners' experiences in the United States. Cogent Business \& Management, 5(1), 1-16. doi:10.1080/23311975.2018.1493903

Chen, C.-M., \& Liu, H.-M. (2017). The moderating effect of competitive status on the relationship between customer satisfaction and retention. Total Quality Management \& Business Excellence, 124. doi:10.1080/14783363.2017.1333413

Chopra, K. (2014). Empirical study on role of customer service in delivering satisfaction at branded retail outlets in Pune. Procedia Economics and Finance, 11, 239-246. doi:10.1016/s2212-5671(14)00192-0

Farnita, I., \& Amri, K. (2013). Persepsi mahasiswa terhadap kualitas layanan Pendidikan Akademi Manajemen Informatika dan Komputer Indonesia (AMIKI) Banda Aceh. Jurnal Ekonomi Manajemen dan Bisnis 1 (1), 118-139

Fida, B. A., Ahmed, U., Al-Balushi, Y., \& Singh, D. (2020). Impact of service quality on customer loyalty and customer satisfaction in islamic banks in the Sultanate of Oman. SAGE Open, 10(2), 215824402091951.

doi:10.1177/2158244020919517

Ghozali, I. (2013). Structural Equition Modelling, Metode Alternatif Dengan Partial Least Square PLS, Badan Penerbit Universitas Diponegoro, Semarang.
Giddens, N., \& Hofmann, A. (2012), Brand Loyalty. (online) http://www. extension.iastate.edu/agdm/wholefarm.

Gong, T., \& Yi, Y. (2018). The effect of service quality on customer satisfaction, loyalty, and happiness in five Asian countries. Psychology \& Marketing, 35(6), 427-442. doi:10.1002/mar.21096

Hutchens, M. J. (2017). Structural Equation Modeling. The International Encyclopedia of Communication Research Methods, 19.

doi:10.1002/9781118901731.iecrm0243.

Ikhsan, Fitri, C. D., Maulana, H., \& Amri, K. (2020). Effect of inflation on total deposits and financing of sharia commercial banks: A monthly data evidence from Indonesia, Regional Science Inquiry 12 (1), 103-114.

Kushwaha, G., Agrawal, S., (2015). An Indian customer surrounding 7P's of service marketing. Journal of Retailing and Consumer Services, 22, 85-95.

Kusumawati, I., Andarwati, \& Hadiwidjojo, D (2017). Pengaruh Kualitas Produk Dan Layanan Terhadap Loyalitas Pelanggan Coffee Shop, Ekonomi Bisnis, 22(2), 123129.

Lentell, R. (2000). Untangling the tangibles: "physical evidence" and customer satisfaction in local authority leisure centres. Managing Leisure, 5(1), 1-16. doi:10.1080/136067100375704

Lin, I. Y., \& Mattila, A. S. (2010). Restaurant servicescape, service encounter, and perceived congruency on customers' emotions and satisfaction. Journal of Hospitality Marketing \& Management, 19(8), 819-841. doi:10.1080/19368623.2010.514547

Loebis, P. H., Utami, S., Basyir, M., Rakhmawati, L., Fahmi, I., Aprilia, C., \& Fauziati, R. (2018). Mediated effect of consumer satisfaction on the influences of experiential marketing and product quality 
on customer loyalty of maybelline cosmetic products in Banda Aceh, Indonesia, Advances in Social Science, Education and Humanities Research, 292, 713-719.

Lovelock, C.H., \& Wright, K. L. (2012) Manajemen Pemasaran Jasa, PT. Indeks, Jakarta.

Maulan, S. (2016). Consumers' loyalty toward islamic banking system: Does halā brand awareness matter?. International Journal of Economics, Management and Accounting, 24(2), 209-226.

Miles, P., Grant, M., dan Alan, C., (2012). Linking servicescape to customer satisfaction: Exploring the role of competitive strategy, International Journal of Operations \& Production Management, 32(7), 772-795.

Mora, O., \& Basyir, M. (2018). Pengaruh healthscape terhadap behavioral intention yang dimediasi oleh service quality pada rumah sakit harapan bunda di Banda Aceh. Jurnal Ilmiah Mahasiswa Ekonomi Manajemen, 3(4), 16-28.

Mukhsina \& Brahmatih, I. A. (2014) The Impact of product, people, process dan physical evidence on customer loyalty at PT. samudera shipping services Surabaya, Jurnal Ilmu Ekonomi \& Manajemen, 1(1), 43-73.

Nashem, T. N., Issa, M. S., Iapadre, G., \& Hamdan, F. I. (2018). Does the physical evidence in emergency department affect the loyalty of the beneficiaries in Jordanian Healthcare Organizations? International Journal of Medical Research \& Health Sciences, 7(7), 151-161.

Oliver, R. (1997). Satisfaction: A behavioural perspective on the consumer. McGraw Hill. New York.

Payne, A. (2000). The Essense of Service Marketing, Alih Bahasa: Fandy Tjiptono, Penerbit Andi, Yogyakarta.
Qanun Aceh No 11 Tahun 2018 tentang Lembaga Keuangan Syariah (LKS)

Ratnawati \& Amri, K. (2013). Pengaruh keadilan organisasional, kepercayaan pada atasan terhadap perilaku kewargaan organisasi (organizational citizenship behavior). Jurnal Ekonomi Manajemen dan Bisnis, 1(1), 56-73.

Shen, X., \& Bae, B-R. (2018). The Effect of Coffee Shop's Servicescape on the Customer Loyalty - Focused on Jeonju Area, International Journal of Industrial Distribution \& Business, 9(3),89-98.

Saeed, R., Iqbal, A., Lodhi, R. N., Sami, A., Riaz, A., Munir, M., \& Mizna. (2014). Impact of service quality on customer loyalty in islamic banking sector of Pakistan: A mediating role of customer satisfaction. Journal of Basic and Applied Scientific Research, 4 (2), 135-143.

Said, M., Hamzah, D., Muis, M., \& Jusni (2016). Implications of establishing location, physical evidence, and customer satisfaction level of customer loyalty in ritel modern In Makassar, International Journal Of Scientific \& Technology Research, 5(1), 107-114.

Sanjaya, S., \& Pratiwi, N. (2018). Pengaruh people, process, dan physical evidence terhadap kepuasan atas pelayanan pada perbankan syariah di kota Padang, AlMasraf: Jurnal Lembaga Keuangan dan Perbankan, 3(2), 194-201.

Slack, N. J., \& Singh, G. (2020). The effect of service quality on customer satisfaction and loyalty and the mediating role of customer satisfaction. The TQM Journal, 32(3), 543-558. doi:10.1108/tqm-072019-0187.

Suhartanto, D., Farhania, N. H., Mufliha, M., \& Setiawan. (2018). Loyalty intention towards islamic bank: The role of religiosity, image, and trust. International Journal of Economics and Management, 12(1), 137-151. 
Susanty, A., \& Kenny, E. (2015). The Relationship between Brand Equity, Customer Satisfaction, and Brand Loyalty on Coffee Shop: Study of Excelso and Starbucks, Asean Marketing Journal, 7(1), 14-27.

Tjan, S. (2015). The impact of marketing mix on customer loyalty towards plaza indonesia shopping center, iBuss Management, 3(2), 392-402.

Verma, Y., \& Singh, M. R. P. (2017). Marketing mix, customer satisfaction and loyalty: an empirical study of telecom sector in Bhutan, Indian Journal of Commerce \& Management Studies, 8(2), 121-129.

Wahid, S. D. M., Mohamad, N. I., \& Zahari, S. N. F. (2012). Measuring physical evidences and customers' satisfactions at hotels \& resorts in Lumut, Elixir Marketing Mgmt. 50, 10253-10256.
Widyarini. (2018). Loyalty of Islamic bank's costumers: A meta-analysis study. Journal of Islamic Economics Lariba, 4(2), 83-96

Xia, Y., \& Yang, Y. (2018). RMSEA, CFI, and TLI in structural equation modeling with ordered categorical data: The story they tell depends on the estimation methods. Behavior Research Methods. doi:10.3758/s13428-018-1055-2.

Ya-Ling Wu, \& Eldon Y. Li,. (2018). Marketing mix, customer value, and customer loyalty in social commerce: A stimulus-organismresponse perspective. Internet Research, 28(1), 74-104.

Yusof, J. M., \& Arifin, S. (2016). The influence of self-congruity, functional image, and emotional attachment on loyalty. Procedia Economics and Finance, 37, 350-357. 